Check for updates

The BMJ

Cite this as: BMJ 2021;373:n1399 http://dx.doi.org/10.1136/bmi.n1399 Published: 01 June 2021

\section{Covid-19: Is it safe to lift all restrictions in England from 21 June?}

\section{Elisabeth Mahase}

England is set to remove all legal limits on social contact from 21 June and allow nightclubs to reopen, although masks may still be required in some public spaces and the test and trace system will continue.

However, the emergence of the B.1.617.2 variant, first detected in India, has led to concerns that further easing may need to be delayed. As cases of this variant spread across the country, The BMJ looks at what we know.

\section{On what basis will the government decide to lift restrictions?}

Although it has given a date for the easing, the government has said that this is about "data, not dates" and that the final decision to list restrictions will be based on four tests ${ }^{1}$ :

- The progress of vaccine deployment

- Sufficient effectiveness of vaccines in reducing hospital admissions and deaths

- Infection rates not putting unsustainable pressure on the NHS, and

- Risks not being fundamentally changed by new "variants of concern."

It's not clear when the final decision will be made on the last stage of easing restrictions. On 27 May England's health secretary, Matt Hancock, said that it was still too early to say, and the prime minister, Boris Johnson, said that nothing in the data currently suggested a need to "deviate from the roadmap, but we may need to wait."2

\section{What do the data on cases and admissions show?}

Latest data from Public Health England (PHE) show that cases of the B.1.617.2 variant have risen by 3535 from 12 May to 19 May, totalling 6959. While Bolton, Bedford, and Blackburn with Darwen still have the highest prevalence, most parts of the country now have cases of the variant. The report says that B.1.617.2 is likely more transmissible than the B.1.1.7 variant, first identified in the UK.

"In some affected areas, hospitalisations are rising," said PHE. "Hospital attendances and admissions are predominantly in unvaccinated individuals, highlighting how crucial it is that people in these areas come forward to receive vaccination.' Around England 201 people with the B.1.617.2 variant had attended emergency departments and 43 had been admitted, as of 25 May. $^{3}$

Chris Hopson, chief executive of NHS Providers, told Times Radio on 26 May, "Trust leaders are telling us that covid-19 hospital cases are increasing steadily in areas most affected by the variant first identified in India but not at an alarming rate...
Hospitalisations clearly seem to be focused amongst those patients who haven't been vaccinated yet.

"The proportion of those requiring critical care is lower than in previous waves, which trust leaders are putting down to the lower age range of patients than in previous covid waves."

However, Neil Ferguson, an epidemiologist at Imperial College London, has said that the B.1.617.2 variant has now overtaken the B.1.1.7 variant to become the dominant variant. He told BBC Radio 4's Today programme on 27 May, "It's now in well over the majority of local authority areas in the country and is now the dominant strain. The majority of new cases are of the variant: that is obviously concerning."

On the same day, Hancock said that as many as three quarters of all new covid-19 cases in the UK involved the B.1.617.2 variant.

\section{What do the latest mortality data show?}

The Office for National Statistics' latest data release reported 151 deaths mentioning covid-19 (1.5\% of all deaths) in the week ending 14 May. This was an increase on 129 deaths the previous week, but the ONS warned that the difference should be "interpreted with caution" because of the early May bank holiday. ${ }^{4}$ Most of the covid-19 related deaths were in people over 75 .

Danny Mortimer, chief executive of the NHS Confederation, said, "Any rise in the number of deaths involving covid-19 is cause for concern, and with reports of rising hospitalisations as the variant first identified in India continues to spread, the [UK] government must think extremely carefully about its next steps.

"If this increase continues, it must be ready to adjust or reverse the timetable for easing lockdown. Given the warnings on the increased transmissibility of the variant, it is also vital that the government goes further to overcome financial barriers to self-isolation in our poorest communities."

\section{Is surge testing making any difference?}

Surge testing has been rolled out in areas considered to have high levels of the B.1.617.2 variant. In these areas, residents and people who are in the area for work or education are encouraged to take a PCR (polymerase chain reaction) test, even if they are not showing symptoms. Additionally, second covid-19 vaccine appointments have been brought forward from three months to eight weeks for people in the nine priority groups.

However, while this is not the first time that surge testing has been rolled out for a variant of concern, ${ }^{5}$ no evidence has yet been made public to show whether it's effective. 


\section{What about surge vaccinations?}

Surge vaccinations-where younger and unvaccinated adults are preferentially targeted for vaccination in areas with high prevalence or rapidly growing outbreaks-have been rolled out in a number of areas in England including Bedford, Bolton, Burnley, Kirklees, Leicester, London, and North Tyneside. ${ }^{6}$

The Scientific Advisory Group for Emergencies (Sage) reviewed surge vaccinations and said that although it could be "operationally challenging" and might slow vaccinations in other parts of the country, the benefit in areas of high variants of concern growth was "many times higher."7

Sage specified that, because of the lag between vaccination and protection, surge vaccinations must be started as soon as possible while the number of variant cases remains relatively low. They should also be targeted at a wider geographical area than where the variant is prevalent, said Sage, and should be accompanied by "short term non-pharmaceutical interventions covering the area in question, to allow for the surge vaccination to have time to take effect.”

\section{How effective are the vaccines against the B.1.617.2 variant?}

A preprint paper released by PHE on 22 May found that, two weeks after the second dose, the Pfizer-BioNTech vaccine was $88 \%$ effective against the B.1.617.2 variant, and the Oxford-AstraZeneca vaccine was $60 \%$ effective. However, both vaccines were only $33 \%$ effective against symptomatic disease from B.1.617.2, three weeks after the first dose. This led to calls for the vaccination programme to be sped up and for the next stage of restriction easing to be delayed. ${ }^{8}$

PHE reported on 27 May that its updated analysis of nearly 3000 symptomatic cases of the B.1.617.2 variant reinforced the message that two doses of either vaccine were "highly effective against the variant first identified in India."

Generally, covid-19 vaccines have so far prevented nearly 40000 hospital admissions and more than 13 ooo deaths in people aged over 60 in England as of 13 May, PHE has estimated.

\section{What do the data on schools show?}

This is exactly what many teachers, unions, and scientists would like to know. The government announced on 10 May that secondary school students would no longer be advised to wear masks in classrooms or communal school spaces from 17 May, but many people have urged them to publish the evidence behind this decision.

In its announcement the Department for Education said, ${ }^{9}$ "Transmission of the virus in schools continues to decrease in line with wider community transmission, with the latest statistics showing a significant drop in the number of teachers and staff testing positive. The decision has taken into consideration the latest scientific evidence, medical advice, and stakeholder feedback on the impacts of wearing face coverings in schools and colleges.”

However, the published version of the PHE report, which looked at the spread of the B.1.617.2 variant, did not include a page of data on the variant's spread in schools that the Observer said it had seen. This led to accusations that this had been removed after pressure from Downing Street. ${ }^{10}$

Eight unions have since written to the government and PHE demanding that they publish the "missing" data. ${ }^{11}$ The letter said, "There are growing concerns around the variant B.1.617.2 and reports from areas such as Bolton that cases are growing fastest amongst school age children, with cases in Bolton higher now than at any point during the pandemic.

"Education unions have repeatedly requested this data since early May. It should have been released in advance of the change in guidance on face coverings, which came into effect on 17 May.”

\section{So, should the final stage of restriction easing go ahead on 21 June?}

Not according to Independent Sage, ${ }^{12}$ which has advised that the next phase of easing should be delayed because only $43 \%$ of adults (30\% of the whole population) have received two doses of the vaccine, and one dose does not offer enough protection.

Its report said, "Unless the risk assessment for B.1.617.2 is downgraded in the coming weeks as more evidence emerges, we believe that step four of the roadmap should be delayed until a much higher proportion of the population has been fully vaccinated or until new evidence of reduced risk emerges.

“Allowing cases to continue to rise will result in a greater burden of long covid, risks the Sage modelling predictions becoming true and risks new variants evolving with higher levels of vaccine escape and/or higher transmissibility. The risk of simply waiting and watching is too high."

Sage previously said that if the variant was found to be more transmissible than the B.1.1.7 variant, which was previously dominant, "it is a realistic possibility that progressing with all roadmap steps would lead to a substantial resurgence of hospitalisations."

Some people have highlighted Israel-where lockdown was eased once $70 \%$ of the population had received two doses-as an example to follow. In the UK, $36 \%$ of the population has had two shots.

Speaking to the Today programme on 28 May, the Independent Sage member Christina Pagel, a mathematician from University College London, said, "If we can just delay international travel, delay stage four of the road map until we have a much higher proportion of people vaccinated with two doses, we're in a much, much better position.”

Cabinet Office. Covid-19 response-spring 2021 (summary). 22 Feb 2021.

https://www.gov.uk/government/publications/covid-19-response-spring-2021/covid-19-responsespring-2021-summary\#step-4---not-before-21-june.

2 Sharman L. Nothing in data to stop June 21 lockdown easing, says Boris Johnson. Evening Standard 2021 May 29. https://www.standard.co.uk/news/uk/coronavirus-latest-dominic-cummings-francequarantine-uk-travel-doctors-backlog-latest-updates-b937490.html.

3 Public Health England. Confirmed cases of COVID-19 variants identified in UK. Updated 27 May 2021. https://www.gov.uk/government/news/confirmed-cases-of-covid-19-variants-identifiedin-uk.

4 Office for National Statistics. Deaths registered weekly in England and Wales, provisional: week ending 14 May 2021. 25 May 2021. https://www.ons.gov.uk/peoplepopulationandcommunity/birthsdeathsandmarriages/deaths/bulletins/deathsregisteredweeklyinenglandandwalesprovisional/weekending14may2021.

lacobucci G. Covid-19: Surge testing for the South Africa variant begins in England. BMJ 2021;372:n305. doi: 10.1136/bmi.n305 pmid: 33531353

6 lacobucci G. Covid-19: Local councils initiate surge vaccination to tackle B.1.617.2 variant. BMJ 2021;373:n1361. doi: 10.1136/bmj.n1361 pmid: 34035001

7 SPI-M-O. consensus statement on covid-19. 12 May 2021. https://assets.publishing.service.gov.uk/government/uploads/system/uploads/attachment_data/file/986709/S1237_SPI-MO_Consensus_Statement.pdf.

8 lacobucci G. Covid-19: Single vaccine dose is 33\% effective against variant from India, data show. BMJ 2021;373:n1346. doi: 10.1136/bmj.n1346 pmid: 34035039

9 Department for Education, Williamson G. Face coverings no longer required in schools and colleges from 17 May. 10 May 2021. https://www.gov.uk/government/news/face-coverings-no-longerrequired-in-schools-and-colleges-from-17-may.

10 Cadwalladr C. No 10 "tried to block" data on spread of new covid variant in English schools. Guardian2021 May 22. https://www.theguardian.com/world/2021/may/22/no-10-tried-to-blockdata-on-spread-of-new-covid-variant-in-english-schools. 
11 Unison. Publish data on school covid variant cases now, say unions. 22 May 2021.

https:/www.unison.org.uk/news/2021/05/government-data-on-covid-variant-cases-linked-toschools-should-be-published-immediately-say-education-unions/.

12 Independent Scientific Advisory Group for Emergencies. The Independent Sage report 42. 25 May 2021. https://www.independentsage.org/wp-content/uploads/2021/05/Indepedent-SageResponse-to-PHE-reports-25-May-2021.pdf.

This article is made freely available for use in accordance with BMJ's website terms and conditions for the duration of the covid-19 pandemic or until otherwise determined by BMJ. You may use, download and print the article for any lawful, non-commercial purpose (including text and data mining) provided that all copyright notices and trade marks are retained. 